\title{
Various sources of methionine in broiler chicken rations
}

\author{
Ivan Koshchaev ${ }^{1, *}$, Kristina Mezinova ${ }^{1}$, Antonina Ryadinskaya $^{1}$, Olga Tatyanicheva $^{1}$, and \\ Natalia Ordina ${ }^{1}$ \\ ${ }^{1}$ Belgorod State Agricultural University, 308503, Vavilova str., 1., Maisky, Belgorod region, \\ Belgorod oblast, Russia
}

\begin{abstract}
Fodder methionine is one of the most important amino acids in animal nutrition, and its deficiency in the ration negatively affects productivity. Currently, the following sources of methionine are represented on the Russian market of feed additives: DL-Methionine and Methionine Hydroxy. Liquid form - Methionine Hydroxy Analog Free Acid (MHA-FA) and dry (for example, MHA) — calcium salt (MHA$\mathrm{Ca} 2+)$. The most popular sources of dry methionine are DL-Methionine and hydroxy analog as calcium salt. Many sources state that the bioavailability of the hydroxy analog varies from 65 to $72 \%$ (one of the manufacturers of the commercial hydroxy analog claims that the availability of methionine is $84 \%$ ). The experiment was carried out on broiler chickens. As a result of the studies carried out, it can be argued that the content of DL-methionine in the ration (in the amount of $65 \%$ of the hydroxyanalogue) in comparison with MHA-Ca increases the productivity of broilers: preservation - by $4 \%$; live weight by $4.3 \%$; average daily gains by $4.6 \%$; feed conversion decreased by $7.1 \%$; has a positive effect on meat productivity. Based on the data obtained during the experiment, it follows that the efficiency of MHA-Ca does not exceed $65 \%$, compared to DLMethionine.
\end{abstract}

\section{Introduction}

At present, industrial poultry farming is one of the main sources of filling the meat and meat products sector in the Russian food market. [1]

The main factor in maintaining the rate of production growth is still a further increase in production efficiency through the introduction of new technologies that reduce production costs, increase the viability and productivity of livestock, as well as a decrease in feed conversion. [2]

Undoubtedly, the main goal is to provide the country's population with high-quality products in full, taking into account the prospects for export, as well as to achieve a high level of social and economic development of the poultry industry.

\footnotetext{
*Corresponding author: koshchaev@yandex.ru
} 
However, despite the significant rates of increase in the production of poultry products, the problem of improving the technology of keeping poultry, rational use of feed, saving material and labor resources remains urgent.

Poultry is considered especially valuable for the opportunity to receive highly nutritious food products from it in short periods of time, with significantly low material costs of feed. So, to obtain $1 \mathrm{~kg}$ of poultry meat gain, feed consumption varies from 1.6 to $1.8 \mathrm{~kg}$. A characteristic feature of poultry growing is its quick maturity and the ability to give a highquality marketable carcass at an early age. [3]

As it is known, in the industrial poultry industry, the main traditional components of compound feed are feed barley, rye, wheat, sunflower and cotton meal and others. Currently, due to the worsening economic situation, feed is used at a low price, but, at the same time, containing components that are difficult to digest (meat flour, cake, barley, sunflower meal, etc.) $10 \%$ lower than traditional corn soybean feed due to the presence of fiber. [4]

Feeding chicks during the first few days after incubation is essential to provide the growing body with the necessary nutrients for normal development of digestive tract and muscle cells.

The high content of nutrients in the feed contributes to the intense functioning of the gastrointestinal tract, which results in diseases of the digestive system. At the same time, intestinal microbiocenosis is disrupted. The microflora of the gastrointestinal tract has colonial resistance, participating in the processes of digestion, providing immunity and detoxification. [5] The rational use of protein by the poultry body depends on the balance of its amino acid composition and the level of availability of amino acids from feed. Protein is the basis for body building and body weight gain in broilers. [6,7]

In modern poultry farming, the priority is to find feeding strategies for broiler chickens that make it possible to use the local raw material base as efficiently as possible, reduce the cost of nutrients for the production of products and improve their quality. The efficiency of feed use by broilers depends not only on the level of amino acids in them, but also on the ratio to methionine and the amount of methionine and cystine to lysine.

It should be noted that it is almost always economically feasible to reduce the level of nutrients, while maintaining their balance, and to increase the dose of feed within the reasonable and possible range to meet the daily needs of the bird. [8]

Determination of the amino acid content in feed is regarded as the main and most important part of the work aimed at improving the meat quality of broilers.

Balancing poultry rations in terms of amino acid composition is one of the most important aspects of effective and cost-effective feeding. [9] Modern broiler crosses have the quite high need for assimilated amino acids.

About 20 amino acids are found in the bird's body proteins. Their various combinations determine a great variety of properties and quality of proteins. About half of these amino acids can be synthesized in the body of the bird. The formation of these, as well as other amino acids that are not involved in the synthesis of proteins, occurs as a result of restructuring of carbohydrates, lipids, organic acids, amino acids, ammonium salts, etc. [10]

Amino acids that can be synthesized in the body of a bird in an amount that meets the needs of the body to maintain its normal existence and for the formation of products are called non-essential.

These amino acids include alanine, glutamic acid, aspartic acid, hydroxyproline, proline, serine, and glycine. [11] It should be noted that the last amino acid is replaceable only for adult birds, but young birds are not able to synthesize it in the required amount.

Some amino acids can be synthesized by poultry in the event that the body has a sufficient amount of other essential amino acids necessary for their formation. Such amino acids are called partially nonessential. This group includes cystine and tyrosine. Cystine can 
be obtained from methionine if there is enough of it in the body, and tyrosine from phenylalanine. $[12,13]$

Consequently, the appropriate supply of cystine and tyrosine to poultry will depend on their intake with food, since these two amino acids are essential. Thus, essential amino acids are not synthesized in the body or are synthesized in a very small amount that does not provide the bird's need for them.

Exept methionine and phenylalanine, essential amino acids for poultry include lysine, threonine, tryptophan, valine, leucine, isoleucine, arginine and histidine, and glycine for young animals. [14]

At present, almost all compound feed for poultry contains one or another source of synthetic methionine, which makes it possible to satisfy the need for sulfur-containing amino acids. [15]

The most popular sources of dry methionine are DL-Methionine and Hydroxyanalogue in the form of calcium salt. Many sources claim that the bioavailability of the hydroxy analog varies from 65 to $72 \%$.

\section{Materials and research methods}

Scientific and economic experience on the influence of various levels of methionine sources on the productivity of broiler chickens was carried out on chickens of the Cobb-500 cross in the conditions of the educational and scientific poultry farm of the UNITS Agrotekhnopark of Belgorod State Agrarian University in September-November 2018

From a batch of chickens of one hatch at one day old, 5 groups of 60 heads each were formed. A total of 5 different rations were tested. The experiment lasted 40 days.

During the experiment, the following indicators were determined:

1. Chemical composition and nutritional value of feed according to generally accepted methods of zootechnical analysis;

2. Main parameters of the microclimate in the poultry house - temperature and humidity;

3. Preservation of livestock - by daily assessment of the clinical and physiological state and registration of dead birds with the establishment of mortality causes;

4. Feed and water intake;

5. Daily rhythm of feed and water consumption;

6. Activity of feed and water consumption;

7. The time spent by the bird at the feeder;

8. Number of bird approaches to the feeder;

9. The live weight of the bird - by individual weighing with an electronic balance when setting up for experiment, at 14, 28, 40 days of rearing;

10. Average daily gain in live weight;

11. Feed costs per $1 \mathrm{~kg}$ of gain over the growing period - by daily accounting of feed consumption;

12. Meat productivity - by control slaughter with complete anatomical cutting;

Microclimate parameters, stocking density, feeding and drinking area were similar for all groups of poultry and corresponded to the normative indicators.

Table 1. Room microclimate parameters

\begin{tabular}{|c|c|c|c|c|}
\hline \multirow{2}{*}{ Day } & \multicolumn{2}{|c|}{ Temperature, ${ }^{\circ} \mathbf{C}$} & \multirow{2}{*}{$\begin{array}{c}\text { Humidity, } \% \\
\mathbf{( 1 7 : 0 0 )}\end{array}$} & Illumination, $\mathbf{~} \mathbf{x}$ \\
\cline { 2 - 3 } & Min & Max & 5 & 6 \\
\hline 2 & 3 & 4 & 66 & 25 \\
\hline 1 & 34.6 & 35.0 & 66 & 25 \\
\hline 2 & 34.0 & 34.5 & 68 & 25 \\
\hline 3 & 33.3 & 33.9 & & \\
\hline
\end{tabular}




\begin{tabular}{|c|c|c|c|c|}
\hline 4 & 33.4 & 33.9 & 70 & 25 \\
\hline 5 & 32.8 & 33.4 & 69 & 24 \\
\hline 6 & 32.4 & 32.8 & 70 & 23 \\
\hline 7 & 31.7 & 32.3 & 68 & 22 \\
\hline 8 & 30.9 & 31.3 & 67 & 21 \\
\hline 9 & 31.5 & 32.1 & 70 & 20 \\
\hline 10 & 29.9 & 30.5 & 69 & 19 \\
\hline 11 & 29.3 & 29.9 & 70 & 18 \\
\hline 12 & 28.8 & 29.2 & 70 & 17 \\
\hline 13 & 28.9 & 29.5 & 71 & 16 \\
\hline 14 & 27.6 & 28.0 & 69 & 15 \\
\hline 15 & 28.7 & 29.3 & 70 & 14 \\
\hline 16 & 27.9 & 28.3 & 68 & 13 \\
\hline 17 & 28.8 & 29.4 & 70 & 12 \\
\hline 18 & 26.0 & 26.6 & 72 & 11 \\
\hline 19 & 27.3 & 27.9 & 68 & 10 \\
\hline 20 & 27.8 & 28.2 & 68 & 10 \\
\hline 21 & 26.9 & 27.5 & 70 & 10 \\
\hline 22 & 26.8 & 27.4 & 68 & 9 \\
\hline 23 & 26.0 & 26.6 & 67 & 9 \\
\hline 24 & 25.6 & 26.2 & 74 & 9 \\
\hline 25 & 25.5 & 26.1 & 74 & 8 \\
\hline 26 & 25.4 & 25.8 & 73 & 8 \\
\hline 27 & 25.1 & 25.5 & 69 & 8 \\
\hline 28 & 25.0 & 25.6 & 74 & 7 \\
\hline 29 & 24.8 & 25.2 & 70 & 7 \\
\hline 30 & 24.4 & 25 & 72 & 7 \\
\hline 31 & 24.9 & 25.3 & 69 & 7 \\
\hline 32 & 24.2 & 24.6 & 71 & 7 \\
\hline 33 & 23.4 & 23.8 & 70 & 7 \\
\hline 34 & 22.8 & 23.4 & 73 & 7 \\
\hline 35 & 22.1 & 22.7 & 72 & 7 \\
\hline 36 & 21.6 & 22.2 & 72 & 7 \\
\hline 37 & 21.0 & 21.4 & 73 & 7 \\
\hline 38 & 20.6 & 21.2 & 71 & 7 \\
\hline 39 & 20.2 & 20.8 & 70 & 7 \\
\hline 40 & 19.8 & 20.6 & 69 & 7 \\
\hline
\end{tabular}

The poultry received rations of the Starter, Rost, Finisher brands. The bird received Starter food from the moment of setting on the experiment, on the 0th (1st) day. The transition from Starter to feed of the Rost brand was made at the age of 10 days by smoothly replacing one feed with another $(70 / 30,50 / 50,30 / 70)$. Then the bird received food Growth up to 22 days of age. From 23 days of age, the bird was smoothly transferred to the Finisher feed (in a similar proportion as in the transition from Starter to Growth) and fed with this type of feed until the end of the experiment. The experiment scheme is presented in Table 2.

Features of feeding broiler chickens were as follows: T1 - Control (negative) - a basic ration deficient in the level of methionine and methionine with cystine in relation to the requirements for the cross;

4 experienced groups:

T2 - Test 1 - basic ration with the addition of MNA-Ca at a dosage of $0.150 \%, 0.110 \%$, $0.095 \%$, according to the growing periods, with a $40 \%$ coverage of methionine deficiency with cystine;

T3 - Test 2 - basic ration with the addition of MNA-Ca at a dosage of $0.375 \%, 0.275 \%$, 
$0.238 \%$, corresponding to the growing periods, with a $100 \%$ coverage of methionine deficiency with cystine;

T4 - Test 3 - standard ration with the addition of DL-Methionine in a dosage (in the amount of $65 \%$ of the dosage level of 1 MNA-Ca in test 1) $0.098 \%, 0.072 \%, 0.062 \%$, according to the growing periods, with a $40 \%$ methionine deficiency covering cystine;

T5 - Test 4 - standard ration with the addition of DL-Methionine in a dosage (in the amount of $65 \%$ of the dosage level of 2 MNA-Ca in test 2) $0.244 \%, 0.179 \%, 0.155 \%$, according to the growing periods, with a coating of $100 \%$ methionine deficiency with cystine.

Table 2. Scheme of the test with a uniform distribution of tested groups in cells in the test building

\begin{tabular}{|c|c|c|c|c|}
\hline \multicolumn{5}{|c|}{ Rations / groups } \\
\hline $\mathrm{T} 1$ & $\mathrm{~T} 2$ & $\mathrm{~T} 3$ & $\mathrm{~T} 4$ & $\mathrm{~T} 5$ \\
\hline 1 & 2 & 3 & 4 & 5 \\
\hline
\end{tabular}

\section{Research results and discussion}

Intensive technology of growing chickens - broilers provides for a decrease in the level of resistance of the organism and an increase in the resistance of the organism to adverse environmental conditions. Established the influence of various sources of methionine on the resistance of the organism of chickens - broilers by taking into account the preservation as a whole for the entire period of the experiment (table 3 ).

Table 3. Preservation of broiler chickens, \%

\begin{tabular}{|c|c|c|}
\hline \multirow{2}{*}{ Ration } & \multicolumn{2}{|c|}{ Preservation by groups } \\
\hline T1 & Group & $\mathbf{1}$ \\
\cline { 2 - 3 } Control & Preservation & 98.3 \\
\hline T2 & Group & $\mathbf{2}$ \\
\cline { 2 - 3 } Test 1 & Preservation & 96.7 \\
\hline T3 & Group & $\mathbf{3}$ \\
\cline { 2 - 3 } Test 2 & Preservation & 93.3 \\
\hline T4 & Group & $\mathbf{4}$ \\
Test 3 & Preservation & $\mathbf{5}$ \\
\hline T5 & Group & 98.3 \\
\cline { 2 - 3 } Test 4 & Preservation & \\
\cline { 2 - 3 } & &
\end{tabular}

The chickens' preservation in the Control and Test groups indicates that the lowest indicators were recorded in the Control, 2nd and 3rd tested groups. The maximum preservation index of $98.3 \%$ was observed in the 4th experimental group, which received DL-Methionine in the highest dosage.

The conditions for feeding and keeping broiler chickens, which are indicators of the growth and development of broiler chickens, are determined by taking into account the live weight of broiler chickens.

Live weight depends on morphological characteristics, nature and degree of physiological processes in the body.

Broiler chickens of the Cobb-500 cross have a genetically inherent ability to accelerate the rate of increase in live weight from 60 to $130 \mathrm{~g}$ per day and, as a result, are distinguished by high levels of live weight.

In this connection, the enterprises must create optimal conditions for the manifestation of the genetic potential of broilers to the full extent and achieve high performance 
indicators by increasing their muscle mass. Indicators of live weight of broiler chickens are presented in table 4.

Table 4. Live weight of broiler chickens

\begin{tabular}{|c|c|c|c|c|c|}
\hline \multirow[t]{2}{*}{ Age, days } & \multicolumn{5}{|c|}{ Live weight by group and ration } \\
\hline & $\begin{array}{c}1 \\
\text { T1 } \\
\text { Control }\end{array}$ & $\begin{array}{c}2 \\
\text { T2 } \\
\text { Test } 1\end{array}$ & $\begin{array}{c}3 \\
\text { T3 } \\
\text { Test } 2\end{array}$ & $\begin{array}{c}4 \\
\text { T4 } \\
\text { Test } 3\end{array}$ & $\begin{array}{c}5 \\
\text { T5 } \\
\text { Test } 4\end{array}$ \\
\hline 1 & 40.1 & 40.0 & 40.4 & 40.6 & 40.5 \\
\hline 14 & 239.3 & 319.2 & 370.6 & 357.7 & 236.0 \\
\hline 28 & 657.1 & 906.6 & 1174.6 & 1042.5 & 654.0 \\
\hline $40(+)$ & 991.8 & 1842.4 & 1936.1 & 1766.8 & 994.1 \\
\hline $40\left(\partial^{\pi}\right)$ & 1162.8 & 2044.0 & 2186.3 & 1926.2 & 1165.7 \\
\hline $\begin{array}{c}40 \\
\text { (average) }\end{array}$ & 1078.7 & 1915.4 & 2038.8 & 1838.3 & 1076.9 \\
\hline
\end{tabular}

Analysis of the chickens' growth dynamics revealed changes in the chickens' growth at different age periods. With practically equal live weight on the first day, at the age of 14 days, the chickens of the second and fourth test groups had higher live weight, which is due to the maximum compliance of the feeding rations with the requirements for cross-country.

At the age of 28 days, the best performance in terms of live weight was shown by the second experimental group, in comparison with the fourth experimental group. At the age of 40 days, the best results were also recorded in the fourth experimental group, which exceeded the results in the second experimental group with MHA-Ca by $4.3 \%$. The chickens of the third experimental group outperformed the birds of the first experimental group by $1.1 \%$.

Average daily gains for growing periods and in general for the entire period are shown in Table 5.

Table 5. Average daily gain in live weight by periods

\begin{tabular}{|c|c|c|c|c|c|}
\hline \multirow[b]{2}{*}{ Period } & \multicolumn{5}{|c|}{ Increases, g/day } \\
\hline & $\begin{array}{c}1 \\
\text { T1 } \\
\text { Control }\end{array}$ & $\begin{array}{c}2 \\
\text { T2 } \\
\text { Test 1 } \\
\end{array}$ & $\begin{array}{c}\text { 3 } \\
\text { T3 } \\
\text { Test 2 } \\
\end{array}$ & $\begin{array}{c}4 \\
\text { T4 } \\
\text { Test } 3 \\
\end{array}$ & $\begin{array}{c}5 \\
\text { T5 } \\
\text { Test } 4 \\
\end{array}$ \\
\hline $1-13$ & 15.3 & 21.5 & 25.4 & 24.4 & 25.9 \\
\hline $14-27$ & 29.8 & 41.6 & 57.0 & 48.5 & 56.5 \\
\hline $28-40$ & 10.5 & 82.8 & 66.8 & 64.8 & 73.4 \\
\hline $1-40$ & 26.6 & 48.1 & 51.2 & 46.1 & 51.6 \\
\hline
\end{tabular}

The analysis of upper table showed that the greatest indicators of the average daily gain in the period from 1 to 40 days were observed in the fourth experimental group compared to the second, where DL-Methionine was added to cover the need for this by $100 \%$, by $0.8 \%$. In comparison of the mass of the first and third experimental groups, the best indicators were revealed in the first by $4 \%$.

In broiler production, accounting for the amount of feed consumed to produce $1 \mathrm{~kg}$ of live weight is important. Payment for feed in live weight is directly related to the profitability of the farm, the efficiency of growing broiler chickens.

The feed cost per unit gain is important from an economic point of view. This is one of the most important indicators of choosing the optimal feeding and breeding program. The optimal diet is made taking into account the need for nutrients per unit of gain in body weight corresponding to a certain segment of the growth curve. With an increase in weight, the animal's need for food to maintain life also changes. At the same time, the feed cost indicator also characterizes the difference in the synthesis of proteins and fats, that is, all 
complex changes in metabolism are reflected in the changes in feed costs for live weight gain.

Table 6. Feed cost per unit of production

\begin{tabular}{|c|c|c|c|c|c|}
\hline Index & $\begin{array}{c}1 \\
\text { T1 } \\
\text { Control }\end{array}$ & $\begin{array}{c}2 \\
\text { T2 } \\
\text { Test } 1\end{array}$ & $\begin{array}{c}3 \\
\text { T3 } \\
\text { Test } 2 \\
\end{array}$ & $\begin{array}{c}4 \\
\text { T4 } \\
\text { Test } 3 \\
\end{array}$ & $\begin{array}{c}5 \\
\text { T5 } \\
\text { Test } 4\end{array}$ \\
\hline Feed eaten, $\mathrm{kg}$ & 139.2 & 204.3 & 216.5 & 223.8 & 223.8 \\
\hline Group growth, $\mathrm{kg}$ & 61.24 & 108.7 & 111.8 & 118.8 & 118.8 \\
\hline Conversion, $\mathrm{kg} / \mathrm{kg}$ & 2.27 & 1.88 & 1.94 & 1.88 & 1.88 \\
\hline
\end{tabular}

The analysis of upper table shows that the consumption of feed of the third experimental group in comparison with the first experimental group exceeded by $9 \%$. The fourth pilot exceeded the second experienced by $3 \%$. The conversion of feed in the fourth experimental was lower than that of the second experimental by $3 \%$, in the first and third experimental it was the same.

To study the meat productivity of broiler chickens from the control and test groups at the age of 40 days, control slaughter and anatomical cutting of carcasses were carried out.

Before slaughter, the bird was kept without food for $8 \mathrm{~h}$, but with free access to water, then individually weighed and looped.

After exsanguination and removal of plumage, the carcasses were washed, cooled to 25 ${ }^{\circ} \mathrm{C}$ and weighed.

During the veterinary and sanitary examination of the carcasses, no pathological changes were revealed.

For control slaughter, 10 chickens were selected from each group ( 5 males +5 females), the live weight of which corresponded to the average live weight in the group (Table 7).

Table 7. Anatomical cutting results (by group)

\begin{tabular}{|c|c|c|c|c|c|c|c|c|}
\hline \multicolumn{2}{|c|}{ Group } & \multirow{2}{*}{$\begin{array}{c}\begin{array}{c}\text { Live } \\
\text { weigh, } \\
\text { g }\end{array} \\
1171.4\end{array}$} & \multirow{2}{*}{$\begin{array}{c}\begin{array}{c}\text { Gutted } \\
\text { carcass } \\
\text { weight, } \mathbf{g}\end{array} \\
745.4\end{array}$} & \multirow{2}{*}{$\begin{array}{c}\begin{array}{c}\text { Slaughte } \\
\text { r yield, } \\
\%\end{array} \\
63.7\end{array}$} & \multirow{2}{*}{$\begin{array}{c}\begin{array}{c}\text { Pectoral } \\
\text { muscle } \\
\text { mass, }\end{array} \\
144.4\end{array}$} & \multirow{2}{*}{$\begin{array}{c}\begin{array}{c}\text { Pecto } \\
\text { ral } \\
\text { muscl } \\
\text { e } \\
\text { yield, } \\
\text { \% }\end{array} \\
19.4\end{array}$} & \multirow{2}{*}{$\begin{array}{c}\text { Thig } \\
\text { h } \\
\text { mass, } \\
\text { g } \\
126.2\end{array}$} & \multirow{2}{*}{$\begin{array}{c}\begin{array}{c}\text { Thigh } \\
\text { yield, } \\
\%\end{array} \\
16.8\end{array}$} \\
\hline \multirow{3}{*}{$\begin{array}{c}1 \\
\text { Control } \\
\text { group }\end{array}$} & Cockerels & & & & & & & \\
\hline & Hens & 1078.4 & 690.6 & 64.1 & 134.0 & 19.4 & 106.2 & 15.4 \\
\hline & Average & 1124.9 & 718.0 & 63.9 & 139.2 & 19.4 & 116.2 & 16.1 \\
\hline \multirow{3}{*}{$\begin{array}{c}2 \\
1 \text { test } \\
\text { group }\end{array}$} & Cockerels & 2061.4 & 1349.6 & 65.6 & 275.4 & 20.5 & 211.2 & 15.6 \\
\hline & Hens & 1811.8 & 1144.6 & 63.2 & 258.0 & 22.3 & 186.8 & 16.3 \\
\hline & Average & 1936.6 & 1247.1 & 64.4 & 266.7 & 21.4 & 199.0 & 16.0 \\
\hline \multirow{3}{*}{$\begin{array}{c}\mathbf{3} \\
2 \text { test } \\
\text { group }\end{array}$} & Cockerels & 2121.8 & 1426.8 & 67.1 & 345.8 & 24.1 & 216.8 & 15.1 \\
\hline & Hens & 2049.2 & 1413.6 & 68.9 & 381.0 & 26.8 & 240.2 & 16.8 \\
\hline & Average & 2085.5 & 1420.2 & 68.0 & 363.4 & 25.5 & 228.5 & 15.9 \\
\hline \multirow{3}{*}{$\begin{array}{c}\mathbf{4} \\
3 \text { test } \\
\text { group }\end{array}$} & Cockerels & 2124.4 & 1458.6 & 68.7 & 331.0 & 22.3 & 254.6 & 17.3 \\
\hline & Hens & 1704.2 & 1135.2 & 66.7 & 259.2 & 22.8 & 184.2 & 16.1 \\
\hline & Average & 1914.3 & 1296.9 & 67.7 & 295.1 & 22.5 & 219.4 & 16.7 \\
\hline \multirow{3}{*}{$\begin{array}{l}\mathbf{5} \\
4 \text { test } \\
\text { group }\end{array}$} & Cockerels & 2203.6 & 1535.2 & 69.7 & 377.0 & 24.5 & 243.2 & 15.9 \\
\hline & Hens & 1989.6 & 1371.8 & 68.9 & 351.2 & 25.4 & 220.8 & 16.0 \\
\hline & Average & 2096.6 & 1453.5 & 69.3 & 364.1 & 24.9 & 232.0 & 15.9 \\
\hline
\end{tabular}

The research investigated the effect of rations on gutted carcass, pectoral and thigh yields. 
The best indicators of meat productivity were found in the 2 nd and 4 th experimental groups. In the 4th experimental group, the carcass and thigh yield is higher by 0.3 and $0.1 \%$ in comparison with the 2 nd group. The yield of the pectoral muscles, on the contrary, is lower by $0.1 \%$.

The results in the 1st and 3rd experimental groups are also practically similar, only the yield of the pectoral muscles in the 3rd group is higher by $0.6 \%$.

\section{Conclusions}

Thus, as a result of the studies carried out, it can be argued that the content of DLMethionine in the ration (in the amount of $65 \%$ of the hydroxy-analogue) in comparison with MHA-Ca increases the productivity of broiler chickens.

- preservation - by $4 \%$;

- live weight by $4,3 \%$;

- average daily gains by $4,6 \%$;

- feed conversion decreased by $7,1 \%$;

- has a positive effect on meat productivity.

Based on the data obtained during the experiment, it follows that the efficiency of MHA-Ca does not exceed 65\%, compared to DL-Methionine.

\section{References}

1. T. O. Azarnova, Poultry and poultry products, 5, 44 - 46 (2019)

2. D. Sun, Pakistan Journal of Zoology, 5, 50 (2018)

3. Gorlov., International Journal of Pharmaceutical Research, 3, 168-173(2020)

4. I. Egorov, International Transaction Journal of Engineering, Management and Applied Sciences and Technologies, 5, 11 (2020)

5. O. A. Gracheva, International Journal of Research in Pharmaceutical Sciences, 1, 908912 (2020)

7. V. Z. Khamitova, Zootechnics, 9, 15-18 (2019)

8. P. H. Selle, Animals, 4, 729 (2020).

9. Ye. A. Basova, Poultry and poultry products, 72, 28-30 (2018)

10. D. Borda-Molina, Poultry Science, 7, 2906-2918 (2019)

11. A. I. Petenko, International Journal of Engineering and Advanced Technology, 6, 5292-5294 (2019)

12. S. I. Nikolayev, Advances in Animal and Veterinary Sciences, 1, 106-111 (2019)

13. R. B. Temiraev, Indo American Journal of Pharmaceutical Sciences, 9, 16006-16010 (2019)

14. V. Kh. Temiraev, Journal of Pharmaceutical Sciences and Research., 12, 2392-2396 (2017)

15. A. A. Shaposhnikov, Research Result: Pharmacology and Clinical Pharmacology, 4, 91-94 (2016) 